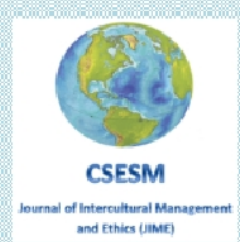

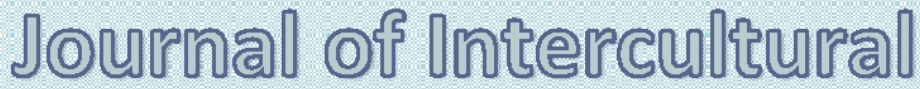

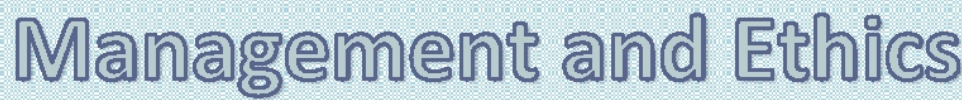

\author{
IOME
}

ISSN 2601 - 5749, ISSN-L 2601 - 5749

\section{published by zy \\ Center for Socio-Economic Studies and Multiculturalism \\ lasi, Romania \\ Waw csesmorg}




\section{Special Editor}

\section{Professor Beatrice Gabriela Ioan, PhD, MD}

Grigore T.Popa University of Medicine and Pharmacy of Iasi, Romania

E-mail: ioanbml@yahoo.com

\section{TABLE OF CONTENT}

Editorial

Beatrice Gabriela Ioan

Global Pandemics: Considerations of Public Health, Human Rights, and Bioethics

SanaLoue

Reactions of Bioethics to the Covid-19 Pandemic 19

Elena Toader, Luiza Palamaru, Tudor Stefan Rotaru, Oana Hrisca Eva

Implications of Cognitive-Behavioural Therapy in Changing Illness Representations .27

Ancuța Elena Păduraru, Camelia Soponaru

Healthcare Workers - Heroes and Villains in Covid-19 Pandemic. The Ethical

Communication

Ioana Silistraru

Ethical Dilemmas in the Therapeutic Management of Patients with Sars-Cov-2 Infection .. 45 Claudia Elena Pleşca, Ioana Hunea, Maria Obreja, Oana Stămăteanu, Delia Luchian, Irina Dima, Larisa Miftode, Tudorița Gabriela Părângă, Egidia Miftode, Simona Apostu, Camelia Bucur, Daniela Leca

Covid - 19 through the Window of Age 55

Elena Toader, Daniela Damir, Tudor Winzinger

Ethical Aspects of "Do Not Resuscitate" Orders in the Context of the Covid-19 Pandemic 61 Iulius Connor Gramma, Gema Bacoanu, Beatrice Gabriela Ioan

Ethics of the Human-Animal Relationship in the Covid-19 Pandemic .67

Cristin Coman, Diana Ancuta 


\title{
COVID - 19 THROUGH THE WINDOW OF AGE
}

\author{
Elena Toader ${ }^{1,2}{ }^{*}$, Daniela Damir ${ }^{1}$, Tudor Winzinger ${ }^{1}$ \\ 1"Gr. T. Popa" University of Medicine and Pharmacy Iași, Romania \\ ${ }^{2}$ Gastroenterology and Hepatology Institute, Emergency County Clinical Hospital Sf. \\ Spiridon, Iași, Romania \\ *corresponding author, e-mail: toader.elena@yahoo.com
}

\begin{abstract}
Ageism involves all aspects of life and it manifests through the manner in which people interact, as well as through our self-perception. Impact of age on social interactions and especially on mental and physical health remains for the most part unknown or underestimated, with a tendency towards homogenized characterization from which derives a risk of damage, exaggeration and even distortion. COVID-19 pandemic generated a complex context in the medical field, with a significant reverberation in the social space, allowing for the assessment of the impact and reaction to a series of ethical values, as well as gathering evidence which, in the area of preconceptions, reflect how COVID-19 pandemic altered the manner to approach ageism. Attitudes towards elders occurring in a series of areas in general, and particularly during COVID-19 pandemic, turn the reality of age into a great challenge. Towards this end, multidisciplinary approaches are necessary, with diverse representations and involvement of all the interested factors, so that we may outline a truthful and accurate portrait of age, for various domains and trials of life.
\end{abstract}

Keywords: ageism, discrimination, care, stereotype, COVID-19

\section{Introduction}

Ageism, also spelled agism, has an influence on all aspects of life and is manifested through the way in which people interact, as well as the manner of perception of the self. Ageism is a social contract of old age which describes elder individuals in a stereotype manner, often negatively inclined, with explicit and implicit assumptions regarding the social group with an aging population, as a stage over the course of life and old as conformity with the development process. Nevertheless, the impact of age on social interactions and specifically on the physical and mental health remains mostly unknown or underestimated, dominated by the homogenous characterization trends, from which derives a risk of damage, exaggeration and even distortion. Starting from the opinions which present ageism as damaging both for involved individuals as well as for the society in its entirety, the most obvious connotations in the definition framework of the term refer to the cognitive dimension represented by stereotypes, with an impact on the emotional dimension, generating prejudice and discriminatory behaviors (Stangl et al., 2019). Additional attempts for a more exhaustive definition of ageism approach its complex nature from the point of view of its positive and negative impact within the framework of possible manifestations at micro, meso and macro level. All these aspects reveal within the relationship between age, stereotype and discrimination multiple exclusions based on age and gender, reformulated as concepts by the COVID-19 pandemic with a series of emphases in the area of connotations on the impact of ageism at the individual level, providing health care, the juridical component and culture (Harper, 2020).

COVID-19, through diverse representations and involvement of all interested individuals, expands approach related to age and brings additions to the outline of portrait as 
realistic as possible of ageism for various spheres and most importantly for various trials of life.

\section{Age and ageing}

Age and ageing have a series of particularities in the network of connections between the individual and the work environment, the manner of relating with the loneliness condition or to adjust to a new social and cultural environment, in the case of immigration, and, last but not least, the experience of life in the third age, aspects which became extremely visible in the pandemic context.

At the individual level, the inner translation of the manner to perceive age is based on the significance of the years ahead and their role on the type of behavior which the individual will adopt. In this approach, the age of 65 is viewed as an age threshold and a landmark of the beginning of ,dependence”, even if many people over 65 years of age live an independent and active life. The potential age expressed by the number of years expected to be lived, reconfigures in the pandemic context the manner of approaching future orientations regarding the reassessment of the process and speed of ageing of the population (Rychtaríková, 2019).

With respect to the professional environment, age articulates at the macro level the historical changes with the modernizations in the domain of industrialized production, with advances in technology and medicine, concurrently with postulations regarding loss of social status and of the up-to-date knowledge based on experience of elder individuals (Rothe, 2012). Covid-19 provided a tough lesson on the potential of elders to access and use technology and medical progress in the absence of paternalist support which would tell them what they can or cannot do. Encouraging the use of modern technologies of information and communication for ageing adults during the pandemic, with the aim to preserve contact with reality and society did not diminish the tendencies of social resistance to assuming a paternalist attitude towards elders (Chen et al., 2021).

Third age, viewed as the golden years of maturity is relatively new in human history, and therefore the experience of life at this age is facing little social comprehension and general guidance. In the literature there are presentations of the association between age, ageing and various ways of migration, revealing the vulnerabilities of older immigrants regarding poverty, issues of physical and mental health and social isolation. Chronologically, third age is a time of life when paradoxically the individual is positively experiencing life and the self, while some cognitive functions slowly deteriorate. In Barnes' opinion, third age is a period with divergent trajectories in life management, where improving of personal values in the areas such as identity, self-esteem, experience, emotional regulation and welfare are countered by the decline of the effort to process and stabilize autonomous cognitive processes (Barnes, 2011). The manner of perceiving COVID-19 in the third age depends on the manner in which the best approaches in geriatrics can be corroborated in a multidisciplinary integrative manner with the best approaches in virology in order to understand the consequences of the crisis in general and in order to elaborate policies adjusted to the specifics of old age.

Ageism and loneliness. Many older adults suffer from loneliness - a painful feeling deriving from the inadequate perception of social connections. The diminishing of their own values that ageing individuals experience makes them vulnerable to loss of self-esteem. The positive feeling towards themselves correlated with the contribution and input to society is questioned by a society which promotes remedies for ageing instead of viewing older individuals as active and having the potential to offer. When loneliness is experienced over long periods of time, it can become devastating for the physical and mental health, often associated with depression, cognitive decline and mortality. It is an alarm signal from the ethical point of view in approaching loneliness, especially in advanced ages, becoming more 
and more a priority in the context of an increasingly ageing world population. In the light of COVID-19 negative stereotypes of age, prejudices and discrimination presented widely call for the strengthening of solidarity actions between generations towards COVID-19 afflicted third age individuals or towards those in isolation, such as home assistance, and insurance of daily necessary things (Liu, Chen, Lin, \& Han, 2020).

\section{The connection between the healthcare system and ageism}

Another level of expression for ageism is the field of healthcare. The connection between the healthcare system and ageism regards ageing as a biological process of senescence caused by gradual deterioration of the body and limitation of mental function. Consequently, the risk of morbidity and mortality increases with age. In the stereotypic belief, old age is viewed as the age of the end of life, when people are for the most part ill, become dependent, are incompetent, poor or alone (Wyman, Shiovitz-Ezra \& Bengel, 2018). This pattern of characterization attributed to elders became a visible model in providing healthcare polarized on age criteria within the context of the COVID-19 pandemic, confronted with exponential increase and progression of severe forms of illness, which led in many countries to dramatic shortages in the intensive care departments. Thus, age limits for intensive care and other forms of medical care proved in many situations inadequate and unethical (Robert et al., 2020).

Ageism and the medication of the elder. Numerous studies report increased rates of adverse events to medication, hospitalization, mortality and higher costs for medical care associated with inadequate usage of medication among older population. A substantial contribution to the increase in the prevalence of medication related issues among older patients is caused by improper prescriptions, polypharmacy and non-adherence to drugs which determine cognitive damage of the balance, with consequent increased risk for falling associated with bone fractures and hospitalizations. Reconfiguration of the medicine and therapeutic condition within the context of the COVID-19 pandemic requires efforts for the investigation of potential motives and the development of action plans for healthcare providers in order to improve concordance with Beers criteria (regarding potentially inadequate medication for older patients) (Alshehri et al., 2020). The Beers Criteria consists of 36 drugs or drug classes that are recommended to be avoided or used only in certain clinical situations and 13 drugs or drug classes that should be used with caution in older adults (Levy \& Barney, 2016). These criteria place an emphasis on the reduction of doses or replacement of unnecessary drugs, thus decreasing the risk for polypharmacy and adverse reactions (Fialová, Kummer, Držaić, \& Leppee, 2018; Harper, 2020).

Ageism and mental health services. Although the impact of age-related stereotypes on the diagnosis of mental health and access to psychotherapeutic care of older adults has not been extensively studied, current practice reveals a series of barriers in the field of mental health services regarding optimal levels of care provided for older adults from both the medical and social perspective (Bodner, Palgi \& Wyman, 2018). From the medical perspective, clinical psychologists express negative opinions regarding the ageing process and certain preferences of older patients. They are described as being rigid, with difficulties in learning, lacking the energy and resistance necessary for therapeutic optimizations. Various assessment studies with standardized case extracts indicated less favorable prognoses for elder patients as opposed to young people. In the sense of interpreting the reality generated by COVID-19 pandemic, the elder are perceived as less than ideal for therapy, from where derives the reluctance of clinical psychologists to work with this category of patients (Harper, 2020; Shmotkin, Eyal \& Lomranz, 1992).

Ageism and dementia. Although dementia is not an unavoidable consequence of ageing, increased age is the main risk factor for this disease (Evans, 2018). The prevalence of 
dementia increases exponentially with age. Statistically, 95\% of patients with Alzheimer's disease, the most frequent form of dementia, are aged over 65 years old (Sampson et al., 2009). Dementia has often strong negative connotations, partially determined by alarmist representations of the illness. Individuals living with this disease usually experience the "double stigma" of age and discrimination correlated with the dementia. The stigma attached to dementia may have significant implications for the quality of life through decrease of social engagement, lowering of self-esteem, increase of the burden on caretakers and under standard medical care, all of which are supplementary aggravated by difficulties generated by the pandemic (Shmotkin, Eyal \& Lomranz, 1992).

\section{Culturality}

A contemporary picture of ageism presents globally current trends of ageing in the population, simultaneously combined with absence of policies oriented towards the effective approach of this issue, in a context where the matter of ageing has become a phenomenon present and widely spread in many cultures. Data in the study of world values, comprising 57 countries, showed that $60 \%$ of the respondents reported the absence of the respect elderly people deserve and should receive (Officer et al., 2016). An explanation towards this end is built on the theme of culturality which, in the context of COVID-19 pandemic, became a factor involved in the escalation of tensions between ageism, individual rights and public health (North \& Fiske, 2015). The overlap with issues related to loneliness, the manner of providing medical care, as well as restrictions from activities and social interaction on age criteria requires from the debate on the COVID-19 agenda the identification of adequate terms for the description of the role of culturality within the wide context of possible life realities.

\section{The juridical aspect}

Ageism and the rights of elderly individuals focus on the elimination of inclusion barriers, of activity restrictions and of the connecting matters. These aspects are still locked within the limits of the objectives of the medical model, mainly oriented towards the disabilities and incompetence of the persons with deficiencies and care needs and less towards ageing policies which would stipulate the reversing of discrimination for the third age. With a contribution towards the exacerbation of discrimination is also the promotion of healthy ageing, which, indirectly, implies the exclusion of the ageing population less healthy (Larsson \& Jönson, 2018). Within the context of the COVID-19 pandemic, the rights of elderly individuals to medical care expressed in external comparisons with the preservation of favorite customs proved to be difficult to maintain when the ageing process is perceived as a change in needs. The COVID-19 pandemic shifted the attention from the performance and capacity of the elderly to the need to make some changes regarding performance and the ability of society to improve policies regarding disabilities, designed to give back the value to the dignity of the elder, in complete agreement with his or her normality, righteousness and personality, which is stereotypically perceived under the aspect of the possibility to live such as it is usual within the context of medical care (Jönson \& Harnett, 2016).

\section{Conclusions}

Ageistic attitudes promoted by public speech during COVID-19 pandemic leave room for a series of interpretations, according to which this pandemic created problems for the individuals aged over 65, who often experience loss of status caused by a perceived correlation with a specific disease. Moreover, the COVID-19 pandemic accentuated exclusion and prejudice against older adults, whose value and contribution to the life of the society is ignored. Within the context of public health, the current pandemic showed the 
manner in which a series of aspects become obvious and highly significant for social stigmatization: negative stereotyping, discrimination and vulnerabilities. Towards this end, we draw the attention towards approaches which increase the solidarity between generations, meant to insure support and social inclusion of older adults, even from the distance.

\section{References}

Alshehri, S., Alshibani, M., Magboul, G., Albandar, A., Nasser, R., Yaqoub, R. M., \& Aljabri, A. (2020). Adherence to Beers Criteria in Geriatrics: A Retrospective Study in a Saudi Teaching Hospital. Geriatrics, 5(4), 97.

Barnes, S.F. (2011). Third Age-The Golden Years of Adulthood. San Diego State University Interwork Institute.

Bodner, E., Palgi, Y., \& Wyman, M. F. (2018). Ageism in mental health assessment and treatment of older adults. Contemporary perspectives on ageism, 241-262.

Chen, A.T., Ge, S., Cho, S., Teng, A.K., Chu, F., Demiris, G., Zaslavsky, O. (2021). Reactions to COVID-19, information and technology use, and social connectedness among older adults with pre-frailty and frailty. Geriatric nursing, 42(1), 188-195.

Evans, S.C. (2018). Ageism and dementia. In Contemporary perspectives on ageism (pp. 263-275). Springer, Cham.

Fialová, D., Kummer, I., Držaić, M., \& Leppee, M. (2018). Ageism in medication use in older patients. In Contemporary perspectives on ageism (pp. 213-240). Springer, Cham.

Harper, S. (2020). The COVID-19 Pandemic and Older Adults: Institutionalised Ageism or Pragmatic Policy?. Journal of Population Ageing, 13(4), 419-425.

Jönson, H., \& Harnett, T. (2016). Introducing an equal rights framework for older persons in residential care. The Gerontologist, 56(5), 800-806.

Larsson, A. T., \& Jönson, H. (2018). Ageism and the rights of older people. In Contemporary perspectives on ageism (pp. 369-382). Springer, Cham.

Levy, H. B., \& Barney, K. F. (2016). Pharmacology, pharmacy, and the aging adult: Implications for occupational therapy. In Occupational Therapy with Aging Adults (pp. 214-234). Mosby.

Liu, K., Chen, Y., Lin, R., \& Han, K. (2020). Clinical features of COVID-19 in elderly patients: A comparison with young and middle-aged patients. Journal of Infection, 80(6), e14-e18.

North, M.S., \& Fiske, S.T. (2015). Modern attitudes toward older adults in the aging world: A cross-cultural meta-analysis. Psychological bulletin, 141(5), 993.

Officer, A., Schneiders, M. L., Wu, D., Nash, P., Thiyagarajan, J. A., \& Beard, J. R. (2016). Valuing older people: time for a global campaign to combat ageism. Bulletin of the World Health Organization, 94(10), 710.

Robert, R., Kentish-Barnes, N., Boyer, A., Laurent, A., Azoulay, E., \& Reignier, J. (2020). Ethical dilemmas due to the Covid-19 pandemic. Annals of intensive care, 10(1), 1-9.

Rothe, P., Lindholm, A. L., Hyvönen, A., \& Nenonen, S. (2012). Work environment preferences-does age make a difference?. Facilities. 30(1/2), 78-95.

Rychtař́ková, J. (2019). Perception of population ageing and age discrimination across EU countries. Population and Economics, 3(1).

Sampson, E.L., Blanchard, M.R., Jones, L., Tookman, A., \& King, M. (2009). Dementia in the acute hospital: prospective cohort study of prevalence and mortality. The British Journal of Psychiatry, 195(1), 61-66.

Shmotkin, D., Eyal, N., \& Lomranz, J. (1992). Motivations and attitudes of clinical psychologists regarding treatment of the elderly. Educational Gerontology: An International Quarterly, 18(2), 177-192. 
Stangl, A.L., Earnshaw, V.A., Logie, C.H., van Brakel, W., Simbayi, L.C., Barré, I., \& Dovidio, J.F. (2019). The health stigma and discrimination framework: a global, crosscutting framework to inform research, intervention development, and policy on health-related stigmas. BMC medicine, 17(1), 1-13.

Wyman, M.F., Shiovitz-Ezra, S., \& Bengel, J. (2018). Ageism in the health care system: Providers, patients, and systems. In Contemporary perspectives on ageism (pp. 193212). Springer, Cham. 